\title{
Structural Integrity Testing Method for PRSEUS Rod-Wrap Stringer Design
}

\author{
John T. Wang ${ }^{1}$ and Ray W. Grenoble ${ }^{2}$ \\ NASA Langley Research Center, Hampton, Virginia, 23681 \\ and \\ Robert D. Pickell ${ }^{3}$ \\ The Boeing Company, Huntington Beach, California, 92647-2099
}

\begin{abstract}
NASA Langley Research Center and The Boeing Company are developing an innovative composite structural concept, called PRSEUS, for the flat center section of a future environmentally friendly hybrid wing body (HWB) aircraft. The PRSEUS (Pultruded Rod Stitched Efficient Unitized Structure) concept uses dry textile preforms for the skins, frames, and stiffener webs. The highly loaded stiffeners are made from precured unidirectional carbon/epoxy rods and dry fiber preforms. The rods are wrapped with the dry fiber preforms and a resin infusion process is used to form the rod-wrap stiffeners. The structural integrity of the rod-wrap interface is critical for maintaining the panel's high strength and bending rigidity. No standard testing method exists for testing the strength of the rod-wrap bondline. Recently, Boeing proposed a rod push-out testing method and conducted some preliminary tests using this method. This paper details an analytical study of the rod-wrap bondline. The rod-wrap interface is modeled as a cohesive zone for studying the initiation and growth of interfacial debonding during push-out testing. Based on the correlations of analysis results and Boeing's test data, the adequacy of the rod-wrap testing method is evaluated, and potential approaches for improvement of the test method are proposed.
\end{abstract}

\section{Introduction}

$\mathrm{T}$ HE NASA Environmentally Responsible Aviation (ERA) program is supporting the development of unconventional aircraft configurations that can improve fuel efficiency through higher lift-to-drag ratio and lower structural weight. One of the main projects of the ERA program is the development of advanced airframe structures for future hybrid wing body (HWB) aircraft. A HWB aircraft configuration proposed by Boeing has a flat center section as shown in Fig. 1 for reducing drag. The flat center section is a box-like flat-sided pressurized cabin constructed with stiffened panels shown in Fig. 2. The circular cross-sectional shape of a conventional aircraft fuselage carries much of the cabin pressure-induced load via hoop-tension in the skin. The flat panels of the HWB center section carry cabin pressure loads via bending. These panels will need much higher bending stiffness than conventional skin-stringer designs. A typical HWB center section panel carries both fuselage and wing bending loads, resulting in a bi-axial loading pattern as shown in Fig. 2. The magnitudes of the loads per unit width are nearly equal in both $\mathrm{x}$ and $\mathrm{y}$ directions, $\left|\mathrm{N}_{\mathrm{x}}\right| \approx\left|\mathrm{N}_{\mathrm{y}}\right|$. Note that a conventional airframe has a cantilevered fuselage that is more highly loaded in the $\mathrm{x}$ direction, along the stringer, than in the y direction, along the frame. Hence, new innovative airframe structural concepts are needed to efficiently carry the loads of an HWB aircraft.

Under the ERA program, engineers at NASA and Boeing are developing a structural concept for the HWB aircraft called Pultruded Rod Stitched Efficient Unitized Structure (PRSEUS) [1,2]. Figure 3 shows that a PRSEUS panel is a highly integrated structure in which the dry warp-knit carbon fabric preforms, precured unidirectionally reinforced composite rods and foam-core materials are assembled, stitched together, and then infused with polymeric resin by way of Boeing's Controlled Atmospheric Pressure Resin Infusion (CAPRI) process [3]. The CAPRI process is a variation of the vacuum assisted resin transfer molding process (VARTM) [4], in which the vacuum level in both the resin supply and vacuum manifolds is controlled, resulting in improved consolidation quality $[1,2]$. Since the stitching can hold the stringer and frame components in place during the CAPRI process, this

\footnotetext{
${ }^{1}$ Aerospace Engineer, Durability and Damage Tolerance Branch, MS 118E, and AIAA Associate Fellow.

${ }^{2}$ Aerospace Engineer, Durability and Damage Tolerance Branch, MS 118E.

${ }^{3}$ Materials, Process \& Physics Engineer, Emerging Technologies, M/C H022-F3XX.
} 
manufacturing process minimizes the necessity for inner mold line (IML) tooling. The presence of the stitching also suppresses the debonding between the skin and the flanges of the stringer and frame; hence, the growth of a discrete source damage, through-the-thickness crack, could be arrested resulting in a significant increase in damage tolerance. The stitching of the stringer and frame preforms to the skin can also resist post-buckling deformation induced out-of-plane failure modes, which allows load carrying well into the post-buckled regime $[2,5,6]$. This increase in damage tolerance and the post-buckling performance allow a PRSEUS panel to carry a greater load than traditional skin-stringer construction. The result should be an overall lighter weight structure.

The frames in a PRSEUS structure are formed from dry fabric preforms over a structural foam core, with the frame lower flanges stitched to the skin in a manner similar to the stringers. At the stringer-frame intersections, the "mousehole" cutouts in the frames can be sized very closely to the shape of the stringer as shown in Fig 3, reducing the effects of these intersections on the overall structural performance. The stringer is formed by wrapping a fabric preform around the teardrop-shaped rod. Below the rod, the fabric forms the stringer web and lower flange. The high axial strength and stiffness of the unidirectional fiber rod in the stringer greatly increases the panel overall bending stiffness by shifting the neutral axis farther from the skin. The frame preform layups are optimized for effectively carrying both the high bending and shear loads [2].

Since the structural integrity of the rod-wrap stiffeners is critical for maintaining the high strength and bending rigidity of the HWB flat cabin panel, any imperfection or debond in the rod-wrap interface bondline could significantly weaken the panel's loading capability. No standard testing method exists for testing the structural integrity of this interface. Recently, Boeing proposed a rod push-out testing method and conducted some preliminary tests on skin-stringer coupons cut from a representative PRSEUS panel. The objective of the present study is to correlate Boeing's test data with analysis results to assess the adequacy of the rod-wrap testing method and identify potential areas for improving the test. In Section II, the testing method, including test specimen configurations and the test set-up, is presented. In Section III, 2D axisymmetric element and 3D solid element models of the test specimen are created and analyzed using $\mathrm{ABAQUS}{ }^{\circledR}$ fracture analysis procedures [7] to predict the rod-wrap interfacial shear strength. In Section IV, correlations of test data and analysis results are performed, and areas for improving the testing method are discussed. In Section V, concluding remarks are given.

\section{Rod Push-out Testing Method}

\section{A. Specimen Configuration and Material Properties}

A sketch of the PRSEUS stringer test specimen configuration is shown in Fig. 4. Note that the stringer web is extended to wrap the rod and the rod has a teardrop shape to minimize the resin buildup at the bottom of the rod. The length of the test specimen along the rod axial direction is $0.5 \mathrm{in}$. The specimens are supported during testing by a one-inch thick aluminum tray, as shown in Fig. 5a. Five specimens are each placed into the tray cavities and are then bonded in place with a potting compound, as shown in Figs. $5 \mathrm{~b}$ and $5 \mathrm{c}$.

The pultruded rods are made of pre-impregnated tape composed of Toray unidirectional T800 fiber and 3900-2B epoxy resin. The stringer webs are made from AS4 fiber preforms infused with HexFlow ${ }^{\circledR}$ VRM 34 resin. The wrap is composed of a single stack of warp knitted preform that has a seven-layer dry carbon fiber $(+45 /-45 / 0 / 90 / 0 /-$ 45/+45) layup. The 0-degree plies are each approximately twice as thick as the other plies. The material properties, shown in Table 1, used for this study are provided by Boeing. Note that the wrap material properties, given in Table 1, are the stack material properties. For the rod and wrap, $E_{1}$ is the elastic modulus in the rod radius direction, $E_{2}$ is the elastic modulus in the rod hoop direction, and $E_{3}$ is elastic modulus in rod longitudinal direction. The rod-wrap interfacial fracture toughness values are not available for the present study. Therefore, typical Graphite/Epoxy properties are used [8]. The epoxy potting compounds are assumed to be Hysol ${ }^{\circledR}$ EA-9396. The material properties for the cured rod, stringer, and potting compound are summarized in Table 1

\section{B. Test Set-up and Results}

The rod push-out test set-up is shown in Fig. 6. The aluminum tray is used to hold specimens for testing. A pushpin applies compression load on an aluminum button to evenly distribute the load on the rod top surface which induces shear stress in the rod and wrap interface (see Figs. 5c and 6). The aluminum button has the same teardropshape as the rod. The bottom of the tray under each specimen has a 0.6 -in diameter hole, concentric with the rod, to allow the rod to be pushed through by the loading pin. Note that the aluminum tray has a very small rim about 0.059-in wide that may provide some support to the bottom corner of the potting compound as shown in Fig. 5c. Boeing conducted preliminary tests on five specimens (\#1 to \#5). During the test, load was applied to the rod end via a steel pin which bore down on an aluminum button as shown in Fig. 6. Preliminary test results, in the form of pushout force and test machine stroke data for four specimens are plotted in Fig 7. Note that an indentation in the top of 
the button was found after each test. The stroke of each test specimen shown in Fig. 7 is adjusted for the indentation depth by assuming that the indentation depth is proportional to the applied force. The test data of specimen\#2 is abnormal, so it is not shown in the figure. The average maximum push-out force for the four tests considered is about 2,800 lbs. Note that the load for each specimen near linearly increases to the maximum and suddenly drops to zero, indicating a brittle fracture failure.

Table 1 Material Properties

\begin{tabular}{|c|c|c|c|c|c|c|}
\hline $\begin{array}{l}\text { Engineering } \\
\text { constants }\end{array}$ & $\begin{array}{l}\text { Rod } \\
\text { Toray } \\
\text { T800/3900- } \\
\text { 2B }\end{array}$ & $\begin{array}{l}\text { Wrap } \\
\text { AS4- } \\
\text { VRM-34 } \\
\text { (Stack } \\
\text { properties) }\end{array}$ & $\begin{array}{l}\text { Isotropic } \\
\text { Properties }\end{array}$ & $\begin{array}{l}\text { Resin } \\
\text { Layer }\end{array}$ & $\begin{array}{l}\text { Potting } \\
\text { Compound } \\
\text { (EA9396) }\end{array}$ & $\begin{array}{l}\text { Rod-wrap } \\
\text { Interfacial Fracture } \\
\text { Toughness }\end{array}$ \\
\hline$E_{1}$ & $1.4 \mathrm{msi}$ & $1.4 m s i$ & $E$ & $0.6 m s i$ & $0.615 \mathrm{msi}^{*}$ & $G_{I C}=0.46 \mathrm{in}-\mathrm{lb} / \mathrm{in}^{2}$ \\
\hline$E_{2}$ & $1.4 \mathrm{msi}$ & $5.07 m s i$ & $v$ & 0.34 & 0.3 & $G_{I I C}=2.85 \mathrm{in}-\mathrm{lb} / \mathrm{in}^{2}$ \\
\hline$E_{3}$ & $18.5 \mathrm{msi}$ & $9.23 m s i$ & & & & \\
\hline$v_{12}$ & 0.4 & 0.01 & & & & \\
\hline$v_{13}$ & 0.01 & 0.01 & & & & \\
\hline$v_{23}$ & 0.01 & 0.4 & & & & \\
\hline$G_{12}$ & $0.8 \mathrm{msi}$ & $2.48 m s i$ & & & & \\
\hline$G_{13}$ & $0.8 m s i$ & $2.48 m s i$ & & & & \\
\hline$G_{23}$ & $0.8 m s i$ & $2.48 m s i$ & & & & \\
\hline
\end{tabular}

*After receiving the $\mathrm{Hysol}^{(B)}$ EA 9396 material data sheet, more analyses were performed using $E=0.4 \mathrm{msi}$.

\section{Finite Element Modeling and Fracture Analysis}

Finite element analyses were performed using ABAQUS ${ }^{\circledR} /$ Standard [7] to simulate the failure of the rod-wrap interface under a push-out load. Modeling, visualization, pre-processing, and post-processing were performed with ABAQUS ${ }^{\circledR} / \mathrm{CAE}$ [9], a graphic user interface (GUI). ABAQUS ${ }^{\mathbb{B}} / \mathrm{CAE}$ was used to create the geometric models of the parts shown in Figs. $5 \mathrm{~b}$ and $5 \mathrm{c}$, including the rod, resin layer, wrap, and potting compound. Then, it was used to mesh the parts, to assign the material properties and the parts' section properties, and to input the rod-wrap interfacial cohesive fracture parameters for simulating debonding initiation and growth. Finally, the ABAQUS $^{\circledR} / \mathrm{CAE}$ was used to assemble the meshed parts, to establish boundary and loading conditions, to create a completed input file for ABAQUS ${ }^{\circledR} /$ standard analysis, and to post-process and visualize the results.

Two-dimensional axisymmetric and three-dimensional solid finite element models were created. These models are shown in Fig. 8. The ABAQUS ${ }^{\circledR}$ axisymmetric element (CAX4 bilinear) was used for the 2D axisymmetric model. The three-dimensional linear brick element (C3D8) was used for the 3D solid element model. In both models, a perfect bond was assumed between the potting compound and the aluminum tray wall, thus all the translational displacements of the outside surface of the potting compound were constrained (fixed). Nonlinear analyses of both models were performed with a uniform displacement loading applied on the top of the rod as shown in Fig. 8. In the 2D axisymmetric model, the rod was assumed to have a circular cross section, and the tail of the teardrop-shaped rod was neglected. The 2D axisymmetric model shown in Fig. 8a is more computationally efficient than the 3D model shown in Fig. 8b. The efficiency will make the 2D model better suited for use in future parametric studies to examine the effects of different shapes of rod and various thicknesses of wrap and potting compound on the rod-wrap interfacial shear strength. Though the 3D solid element model is more difficult to create and the results need to be transformed to the proper coordinate systems for visualization, it is needed for obtaining a correct stress distribution in the rod-wrap interface, and therefore is essential for accurate prediction of the failure load.

For the 2D axisymmetric model, the interface between the rod and wrap was modeled as a cohesive zone with either the ABAQUS ${ }^{\circledR}$ cohesive surface or the cohesive element approach [7]. In the cohesive surface approach, the cohesive zone was assumed to have zero thickness, and the corresponding contacted surfaces were modeled as master and slave surfaces that are connected with the surface-based cohesive behaviors. In the cohesive element modeling approach, the resin layer between the rod and wrap was modeled with 4-node axisymmetric cohesive elements (COHAX4). In the 3D solid element model, the cohesive zone was modeled with the cohesive surface 
approach only. Unlike the virtual crack closure technique (VCCT) [10], the cohesive zone modeling approach does not require the assumption of an initial debond length. The initiation of interfacial debonding failure as well as the subsequent debonding growth can be simulated with the cohesive law provided. The bilinear cohesive law for each fracture mode used in this study is shown in Fig. 9 [9,11-13], including the peel failure mode and two shear failure modes. In Fig. $9, \tau^{C}$ is the maximum traction, $\Delta^{f}$ is the maximum separation, and the area under the cohesive law is the critical energy release rate. In this study, an elastic constant of $1.4 \times 10^{8} \mathrm{lb} / \mathrm{in}^{3}$ is assigned for the rising slope of the cohesive law of the normal traction and an elastic constant of $8.0 \times 10^{7} 1 \mathrm{~b} / \mathrm{in}^{3}$ is assigned for the rising slopes of both cohesive laws of the two shear tractions. These values were intentionally selected to be high for minimizing the effect of the elastic deformations on the cohesive zone analysis results.

Damage initiation for both the cohesive surface and cohesive element modeling approaches is based on a quadric stress criterion [7]

$$
\left\{\frac{\left\langle\tau_{n}\right\rangle}{\tau_{n}^{C}}\right\}^{2}+\left\{\frac{\tau_{s}}{\tau_{s}^{C}}\right\}^{2}+\left\{\frac{\tau_{t}}{\tau_{t}^{C}}\right\}^{2}=1
$$

where $\langle$.$\rangle is the Macaulay bracket defined as \left\langle\tau_{n}\right\rangle=\frac{1}{2}\left(\left|\tau_{n}\right|+\tau_{n}\right), \tau_{n}$ is the normal traction, and $\tau_{s}$ and $\tau_{t}$ are the two shear tractions. $\tau_{n}^{C}$ is the maximum normal traction, and $\tau_{s}^{C}$ and $\tau_{t}^{C}$ are the two maximum shear tractions. In this study, the values of $\tau_{n}^{C}=4.0 \times 10^{3} \mathrm{ksi}, \tau_{s}^{C}=7.0 \times 10^{3} \mathrm{ksi}$, and $\tau_{t}^{C}=7.0 \times 10^{3} \mathrm{ksi}$ were used. These values were selected to assure that the brittle fracture of the Boeing test specimens could be represented appropriately. Fully developed processing zone lengths for individual fracture modes are estimated to be about one hundredth of an inch [11]. Researchers have shown that the fracture prediction, using a cohesive law with a short fully-developed-processingzone length [11,14], is compatible to that predicted by the linear elastic fracture mechanics [14-17].

In this study, the damage evolution, degradation of the cohesive stiffness, along the softening branch of the cohesive law was determined based on the mixed mode fracture energy [7, 13]. The mixed mode fracture energy is given as

$$
G_{\text {mixed }}=1 /\left[\left\{\frac{m_{1}}{G_{n}^{C}}\right\}^{2}+\left\{\frac{m_{2}}{G_{s}^{C}}\right\}^{2}+\left\{\frac{m_{3}}{G_{t}^{C}}\right\}^{2}\right]^{1 / 2}
$$

where $m_{1}=G_{n} / G_{T}, m_{2}=G_{s} / G_{T}$ and $m_{3}=G_{t} / G_{T} . G_{n}$ is the energy release rate of the normal mode, $G_{s}$ and $G_{t}$ are the energy release rates for the two shear modes, and $G_{T}=G_{n}+G_{s}+G_{t}$ is the total energy release rate. The values of critical energy rates used are $G_{n}^{C}=0.46 \mathrm{in}-1 \mathrm{~b} / \mathrm{in}^{2}$ and $G_{s}^{C}=G_{t}^{C}=2.85 \mathrm{in}-1 \mathrm{~b} / \mathrm{in}^{2}$. These values are consistent with those of an AS4/3501-6 graphite-epoxy material system [8]. Note that a VCCT analysis with an assumed debond length of 0.03 inches predicts that the mode II critical energy rate is about $2.3 \mathrm{in}-\mathrm{lb} / \mathrm{in}^{2}$, using an estimated average force level about 2,300 lbs at which the loading curves shown in Fig. 7 start to turn nonlinearly. Here, the turning point is assumed to be caused by the initiation of debonding between the rod-wrap interface. The VCCT analysis indicates that the fracture toughness properties used are reasonable. More accurate energy release rates will be available from future material characterization tests. Damage propagation occurs once the following power law criterion is satisfied $[7,18]$

$$
\left\{\frac{G_{n}}{G_{n}^{C}}\right\}^{2}+\left\{\frac{G_{s}}{G_{s}^{C}}\right\}^{2}+\left\{\frac{G_{t}}{G_{t}^{C}}\right\}^{2}=1
$$

\section{Analysis Results and Correlations with Test Data}

Analysis results from the 2D axisymmetric and 3D solid element models were first obtained with the assumption of a perfect bonding between the potting compound and the aluminum tray wall. The boundary conditions for both models are given in Fig. 8. In each analysis, a uniform displacement was applied on the top surface of the rod to gradually push down the rod until it completely separated from the wrap. The rod wrap interfacial stress is 
dominated by shear stress in the resin layer between the rod and wrap as shown in Figs. 10-12. As the rod starts separating from the wrap, the high shear stress band gradually moved downward. Detailed 3D solid element model results shown in Fig. 12a reveal that there is a high shear stress concentration near the tail of the teardrop-shaped rod. The stress concentration increases the debond growth rate in that region. The deformation plots in Figs. 12a and $12 \mathrm{~b}$ show that the rod is gradually separated from the wrap as the stroke (push-out displacement) increases.

The reaction forces of all the finite element nodes on the loaded end of the rod were summed together to obtain the push-out force. The maximum push-out forces (failure loads) obtained from the 2D axisymmetric model, using both the cohesive surface and cohesive element approaches are shown in Fig. 13. The 2D model maximum load predictions are higher than those of the 3D solid element model because of the stress concentration at the base of the teardrop in the 3D solid element model. That feature was neglected in the 2D axisymmetric model.

The failure loads of four test specimens are compared with the finite element analysis predictions in Fig. 14. The model predictions of the failure load differ from the average measured values by approximately $5 \%$. This good correlation indicates that the rod push-out testing method may be adequate for evaluating the rod-wrap interfacial shear strength. However, the fracture properties used for these predictions need to be further confirmed. The strokes, predicted by the finite element models, shown in Fig. 13 are much less than those recorded in the test (see Fig. 7). The causes of this discrepancy may include the uncertainty of the supporting boundary conditions, the inaccuracy of the potting compound material properties, and the compliances of the test machine and fixture.

A failed specimen, sectioned through the center of the rod, is shown in Fig. 15. The top part of the sectioned specimen can easily be removed from the aluminum tray indicating that the bonding between the potting compound and the aluminum tray has failed. Whether the failure occurred before or during the test is unknown. To study the effect of the bondline failure, the 2D axisymmetric model was altered by freeing all degrees of freedom of the rightside edge nodes of the potting compound. The edge's bottom corner node was still supported. Note that the aluminum tray has a very small rim of 0.059 -in wide to support the bottom corner of the potting compound as shown in Fig. 15. In this new analysis, the contact between the potting compound and the aluminum tray wall was also modeled.

The load-stroke curves shown in Fig. 16 show that the changes to the model result in a significant increase in the stroke predicted. Note that two different Young's moduli, $615 \mathrm{ksi}$ and $400 \mathrm{ksi}$, were used in the analyses to study the effect of changing the potting compound material properties. Fig. 16 shows that lowering the modulus of the potting compound can significantly increase the stroke predictions. The 2D axisymmetric model did not predict a significant change in the maximum failure load due to bondline failure or the change of the potting compound Young's modulus. The analysis result, for the model with the potting compound Young's modulus of $400 \mathrm{ksi}$, is shown in Fig. 17, along with the test data. Correlation between the analysis and test is much improved. It could be concluded that the bonding quality between the potting compound and the aluminum tray and the material properties of the potting compound need to be accurately characterized for obtaining better test and analysis correlations. Unfortunately, assessment of bondline quality will be very difficult because the available nondestructive inspection (NDI) techniques cannot be adequately applied deep within the aluminum block. One possible alternative is to increase the size of the cavities in the block while keeping the diameter of the exit hole the same to provide a much wider supporting rim. A larger volume of potting compound could be molded to the test specimen. The thicker potting material can provide a larger supporting area at the bottom of the specimen to eliminate a potential nonlinear material deformation in the supporting area. The wall of each cavity could be coated with a non-stick coating, so there is no bond between the wall and the outer surface of the potting compound. The boundary conditions at the outer surface of the potting compound can be assumed as free. Hence, measured displacements would no longer be dependent on bondline quality between the potting compound and the aluminum block. Furthermore, the compliances of the testing machine and the loading pin will also affect the stroke data, so the displacement should be measured directly instead of being inferred from the stroke data.

\section{Concluding remarks}

The HWB aircraft requires innovative structural concepts such as PRSEUS to provide high bending rigidity for its box-like center cabin. PRSEUS stiffened structural panels can provide the structural efficiency required by this application. In the present study, FE models were developed to study the Boeing-developed test method for measuring the shear strength of the rod-wrap interface. The test method uses a short section of the rod-wrap stringer, which is bonded into a cavity in an aluminum block. Interfacial shear strength is assessed by applying a load to one end of the rod, which pushes the rod out through a hole at the bottom of the aluminum tray.

Two-dimensional and three-dimensional finite element models of the test configuration were created. The correlations between the model predictions and the test data demonstrated that the newly available ABAQUS ${ }^{\circledR}$ 
cohesive debonding analysis capabilities could have the potential to accurately predict the interfacial shear strength of the PRSEUS rod-wrap interface. Although a VCCT analysis, performed at the debond initiation load, indicates that the fracture toughness properties used in the analyses are reasonable, they still need to be experimentally confirmed before the accuracy of the analysis presented could be assessed. The cohesive surface element approaches do not require the assumption of an initial debonding defect length, which reduces the effort of model creation.

Initial analyses assumed perfect bonding between the potting compound and the cavity wall of the aluminum block holding the specimen. The resultant failure loads were within approximately $5 \%$ of the average test failure loads of four specimens. Note that the fracture properties used in these predictions considered being reasonable, they need to be further confirmed. This good correlation indicates that the rod push-out testing method may be adequate for evaluating the rod-wrap interfacial shear strength. However, the FE models predicted strokes that were much less than the test data. Examination of failed test specimens showed that the bond between the potting compound and the aluminum block had failed. A 2D analysis was subsequently performed by assuming that there was no bonding between the potting compound and the wall of the aluminum tray. The predicted displacements increased by nearly an order of magnitude, and therefore were in much closer agreement with the test data. Further analyses indicated that the predicted strokes were highly sensitive to the modulus of the potting compound. Accurate measurement of the mechanical properties of the potting compound and confidence in the bonding quality between the block wall and the potting compound will be required to improve the accuracy of the stroke predictions.

A simple method of eliminating the latter uncertainty is to increase the size of the cavities in the block and to coat them with non-sticking material. Each specimen will be encapsulated within a larger volume of potting compound. This modified geometry provides a larger supporting surface for the bottom of the specimen. Furthermore, the lack of bond between the compound and the block wall establishes known boundary conditions. Future analyses using these well-defined boundary conditions and better material properties from an ongoing material characterization program are expected to show improved correlation between the FE analysis predictions and test data for strength and stroke. Here, the stroke is a direct measurement of the rod's top-surface displacement to eliminate the effect of the machine compliance.

\section{References}

1. Velicki, A., and Thrash, P. “Advanced Structural Concept Development Using Stitched Composites," Proceedings of $49^{\text {th }}$ AIAA/ASME/ASCE/ASC Structures, Structural Dynamics, and Materials Conference, Schaumburg, IL, 7-10 April 2008.

2. Velicki, A., Thrash, P., and Jegley, D.C., “Airframe Development for Hybrid Wing Body Aircraft," Proceedings of $47^{\text {th }}$ AIAA Aerospace Sciences Meeting Including the New Horizons Forum and Aerospace Exposition, Orlando, Florida, 5-8 January 2009.

3. Woods, J., Modin, A. E., Hawkins, R. D., and Hanks, D. J., "Controlled Atmospheric Pressure Infusion Process," International Patent WO 03/101708 A1.

4. Hoebergen, A., and Holmberg, J. A., "Vacuum Infusion," ASM Handbook, Vol. 21, Composites, 2001.

5. Velicki, A, "Damage Arresting Composites for Shaped Vehicles," Phase I Final Report, NASA/CR-2009-215932, September 2009.

6. Jegley, D. C., Velicki, A., Hansen, D., "Structural Efficiency of Stitched Rod-stiffened Composite Panels with Stiffener Crippling," Proceedings of $49^{\text {th }}$ AIAA/ASME/ASCE/SHS/ASC Structures, Structural Dynamics, and Materials Conference, Schaumburg, IL, 7-10 April 2008.

7. ABAQUS Analysis User's Manual, Version 6.11, ABAQUS Inc., 2011.

8. Reeder, J. R., “A Bilinear Failure Criterion for Mixed Mode Delamination," Composite Materials: Testing and Design, Eleventh Volume, ASTM STP 1206, American Society for Testing and Materials, December 1993, pp. 303-322.

9. ABAQUS/CAE User's Manual, Version 6.11, ABAQUS Inc., 2011.

10. Rybicki E. F., Kanninen M. F., "A Finite Element Calculation of Stress Intensity Factors by a Modified Crack Closure Integral," Engineering Fracture Mechanics, Vol. 9, 1977, pp. 931-938.

11. Hillerborg, A., Modeer, M., and Petersson, P. E., "Analysis of Crack Formation and Crack Growth in Concrete by Means of Fracture Mechanics and Finite Elements," Cement and Concrete Research, Vol. 6, 1976, pp. 773-782.

12. Turon, A., Davila, C. G., Camanho, P. P., and Costa, J., "An Engineering Solution for Mesh Size Effects in the Simulation of Delamination Using Cohesive Zone Models," Engineering Fractures Mechanics, Vol. 74, 2007, pp. 16651668.

13. Camanho, P. P., Davila C. G., and de Moura M. F., "Numerical Simulation of Mixed-Mode Progressive Crack in Composite Materials," Journal of Composite Materials, Vol. 37, 2003, pp. 1415-38.

14. Wang, J. T., "Investigating Some Technical Issues on Cohesive Zone Modeling of Fracture," Proceedings of $52^{\text {nd }}$ AIAA/ASME/ASCE/AHS/ASC Structures, Structural Dynamics, and Material Conference, Denver, CO, April, 4-7, 2011.

15. Rice, J. R., "A path independent integral and approximate analysis of strain concentration by notches and cracks," ASME Journal of Applied Mechanics, Vol. 35, 1968, pp. 379-386. 
16. Hutchinson, J. W., A course on nonlinear fracture mechanics, Department of Solid Mechanics, The Technical University of Denmark, Lyngby, Denmark, 1979, pp. 12-13.

17. Bao, G., and Suo, Z., "Remarks on crack-bridging concepts," Applied Mechanics Review, Vol. 45, No. 8, August 1992, pp. 355-366.

18. Wu, E. M., and Reuter, R. C. Jr., "Crack Extension in Fiberglass Reinforced Plastics," T and M Report, University of Illinois, Vol. 275, 1965.

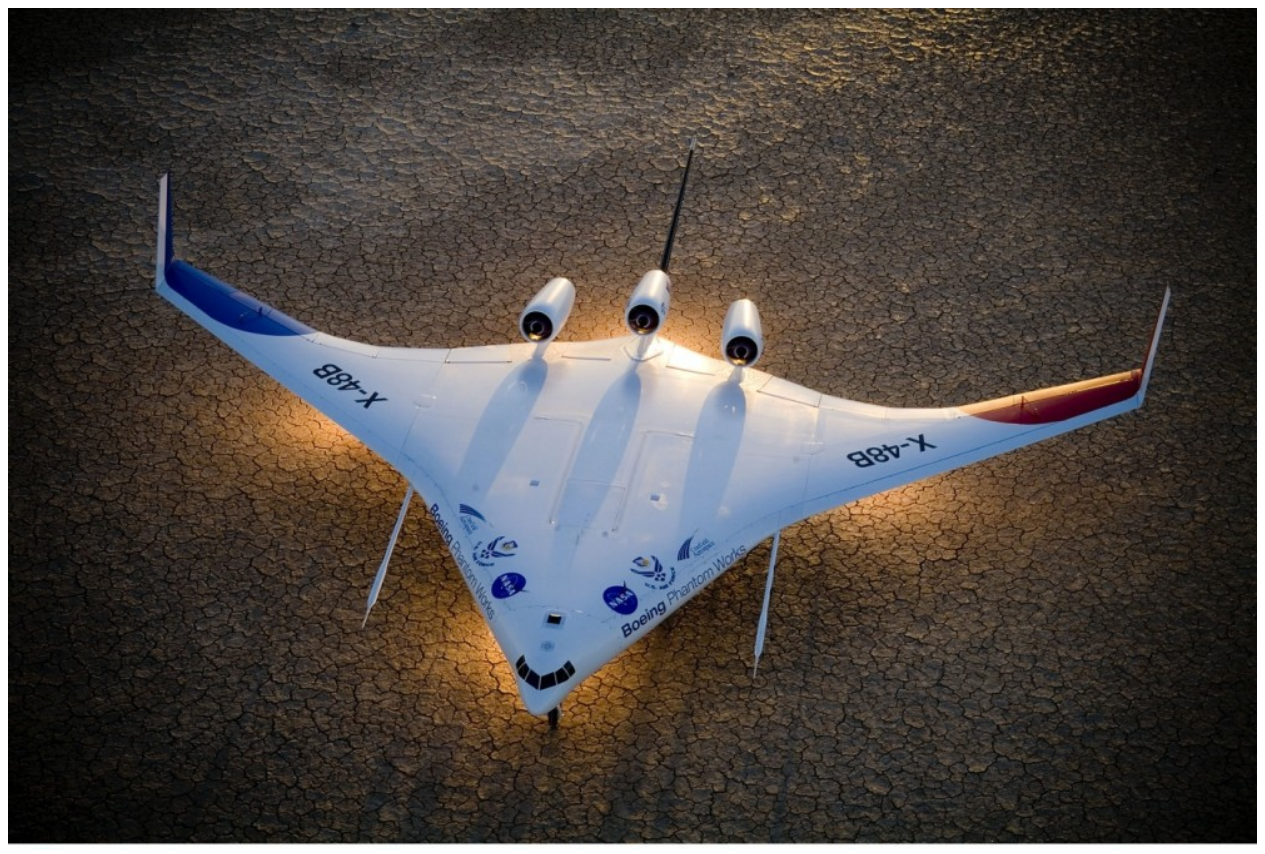

Fig. 1 Configuration of an experimental hybrid wing body aircraft (NASA Dryden Flight Center Photo Collection).

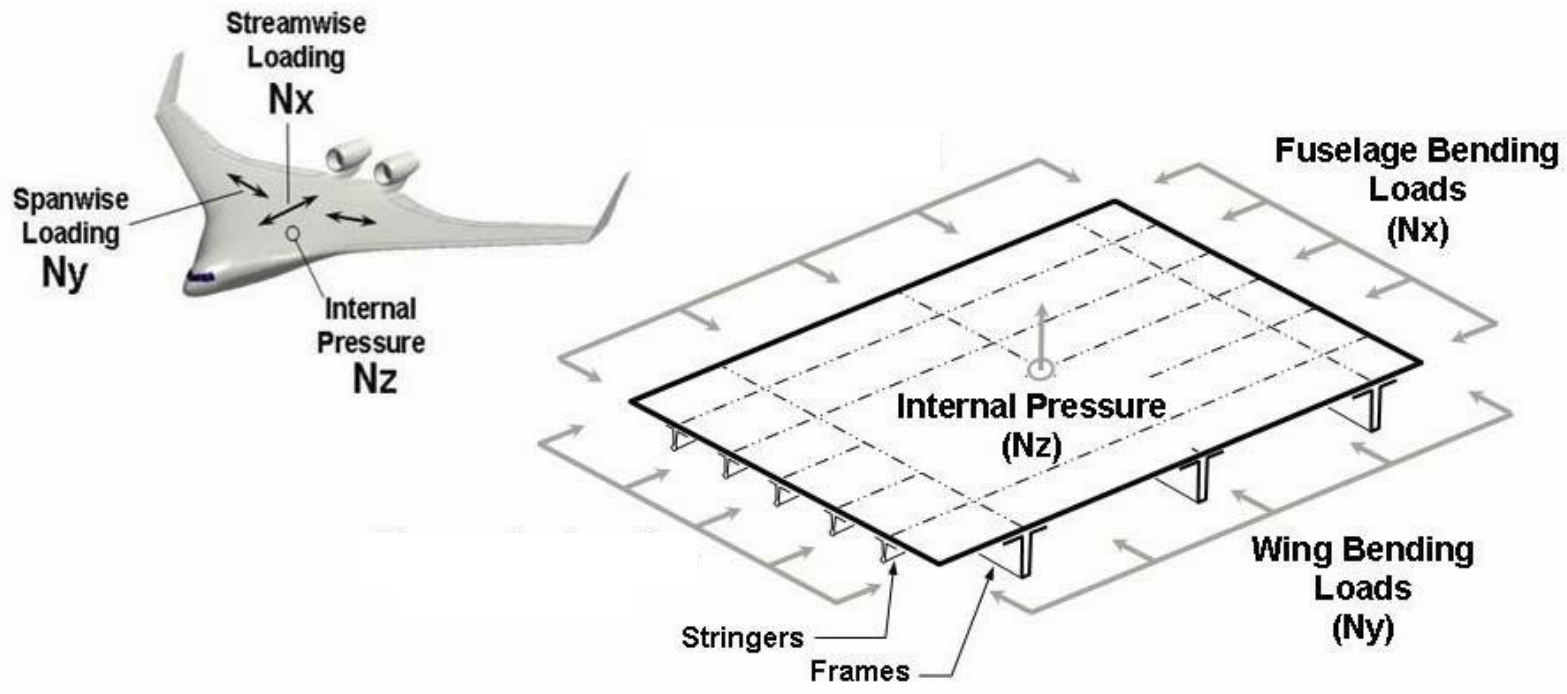

Fig. 2 Hybrid wing body aircraft using flat stiffened fuselage panel [1,2]. 


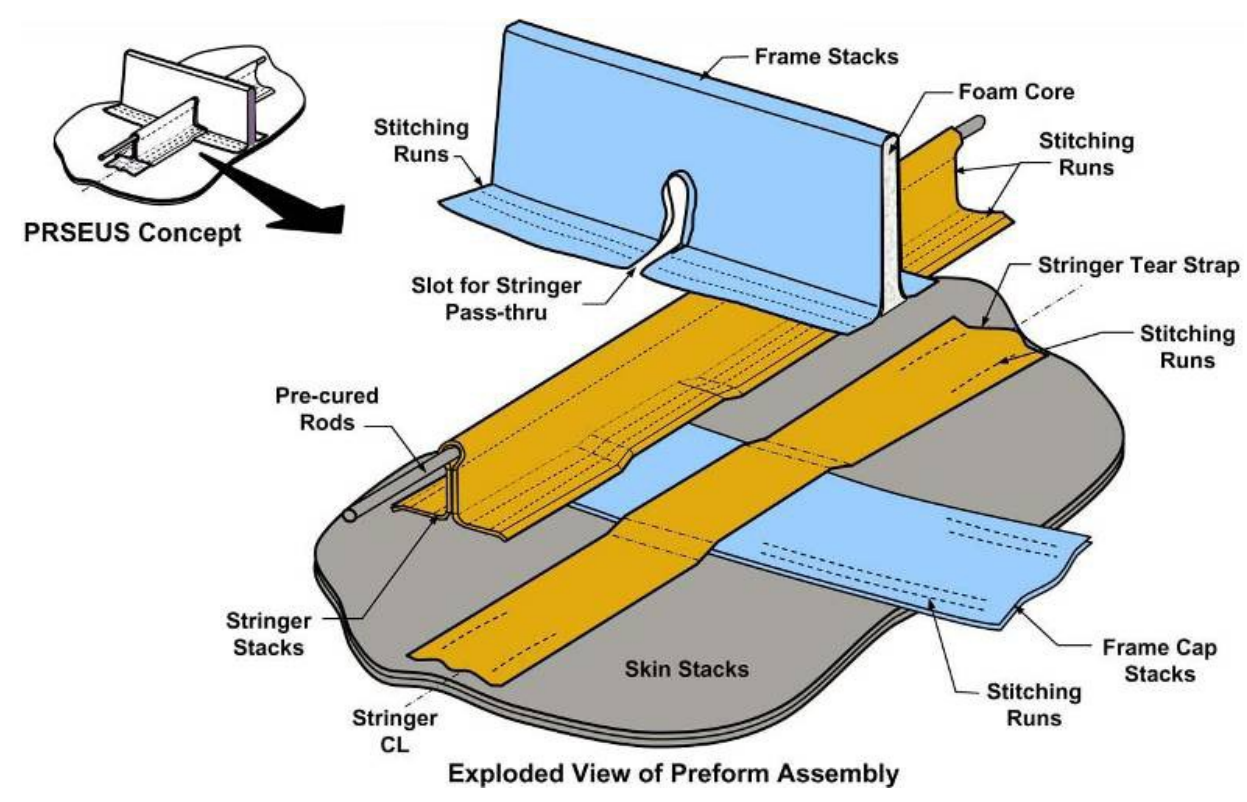

Fig. 3 Exploded view of stringer-frame intersection of PRSEUS panel [1,2].

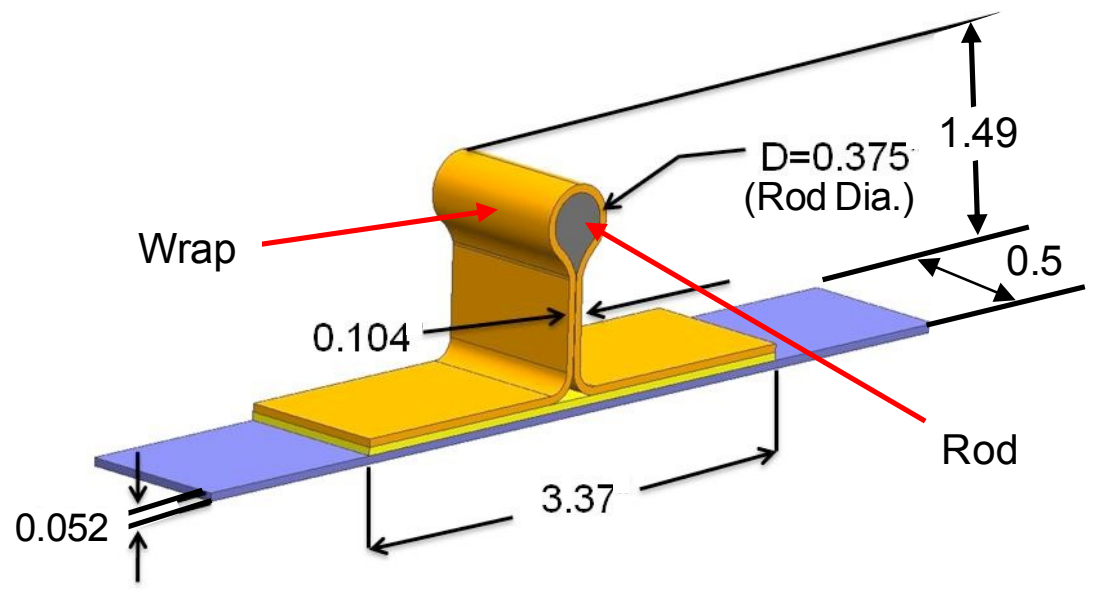

(Dimensions in inches)

Fig. 4 PRSEUS rod-wrap stringer specimen configuration. 


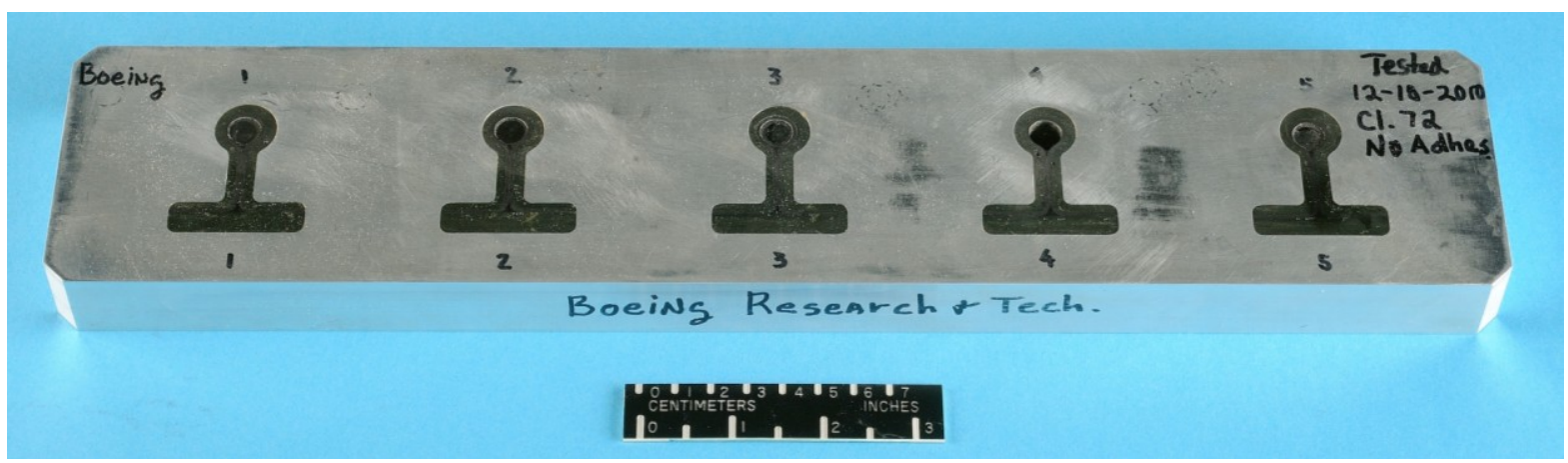

a) Test specimens in aluminum tray

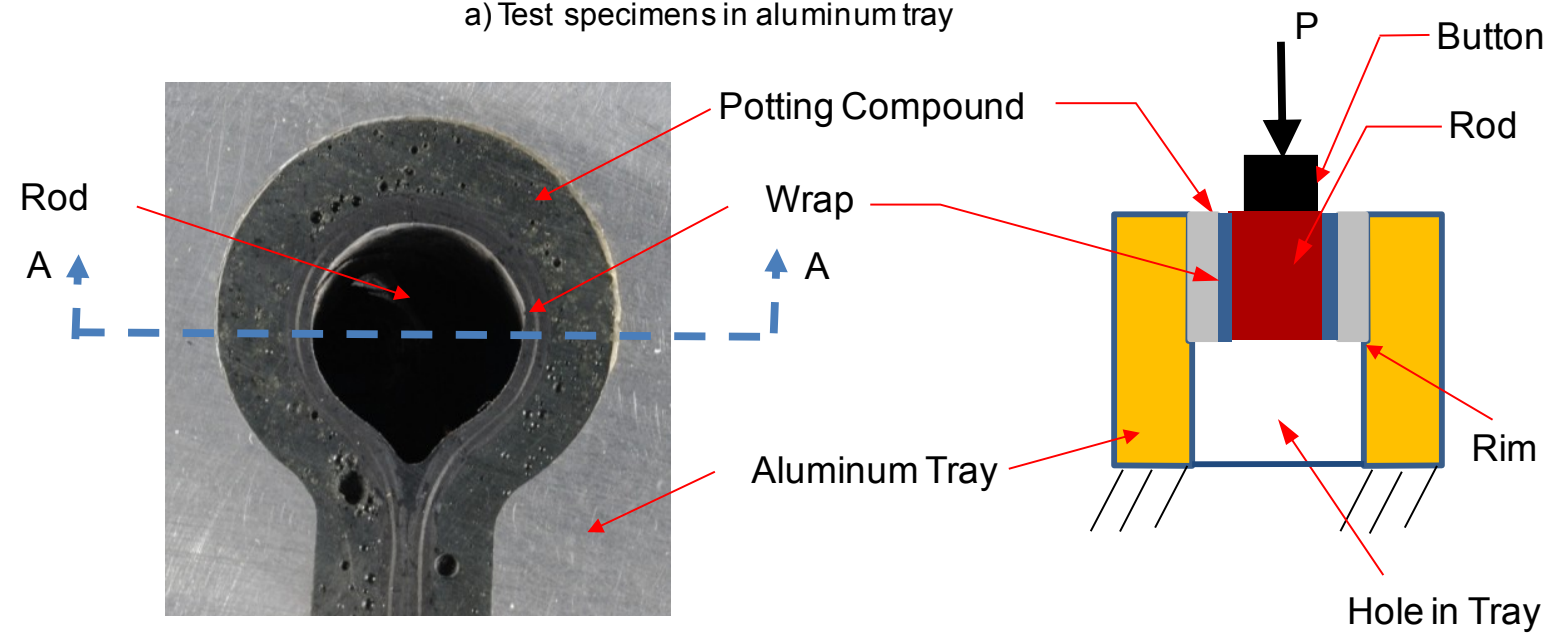

b) Top view of test specimen

c) Section A-A

Fig. 5 Test specimens and aluminum tray.

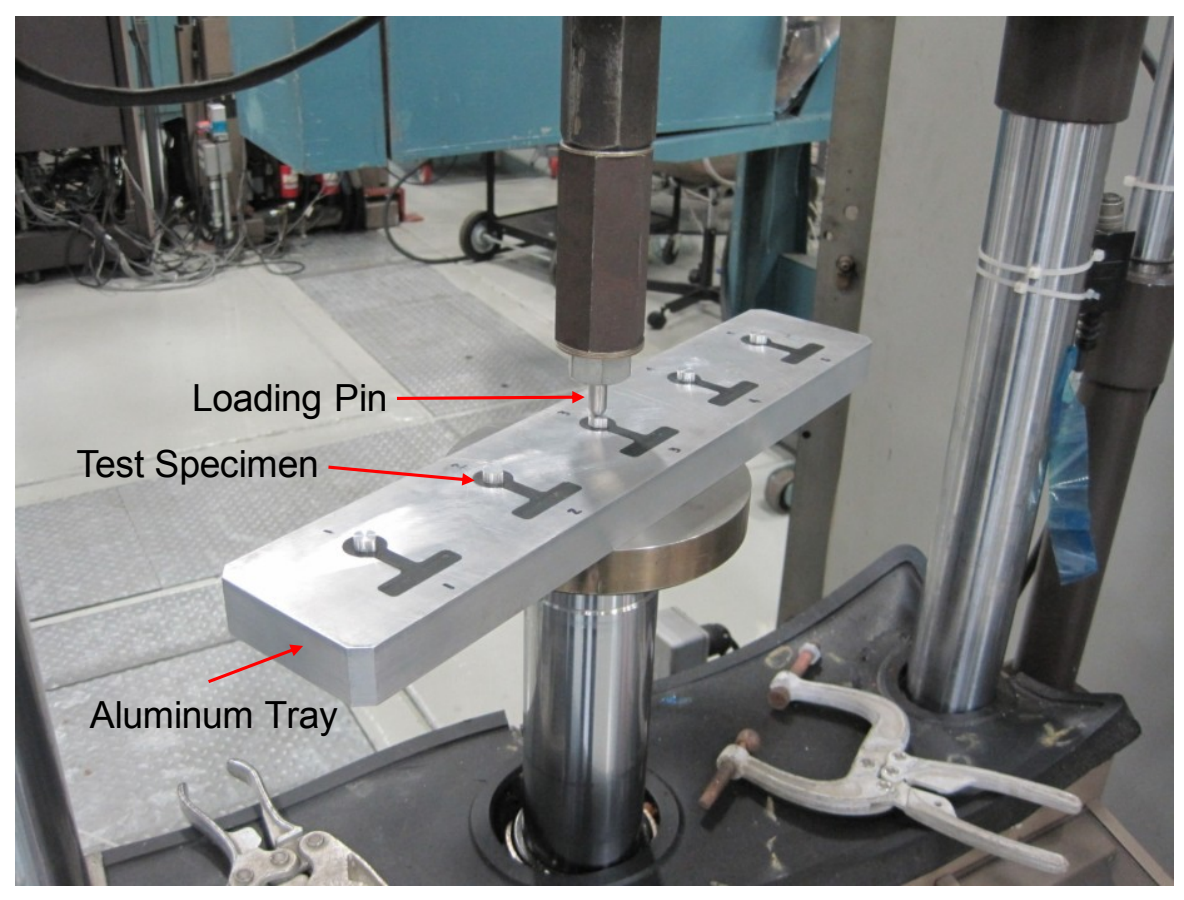

Fig. 6 Rod push-out test set-up. 


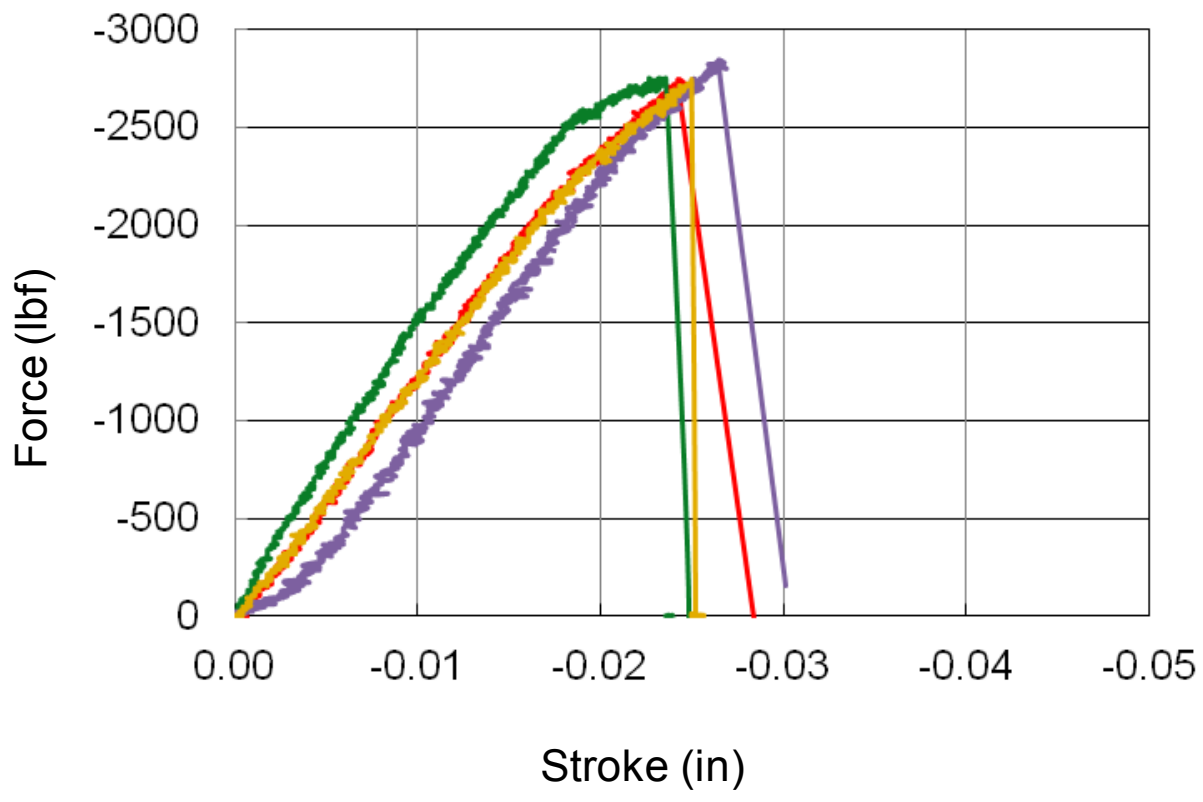

Fig. 7 Preliminary rod push-out test results.

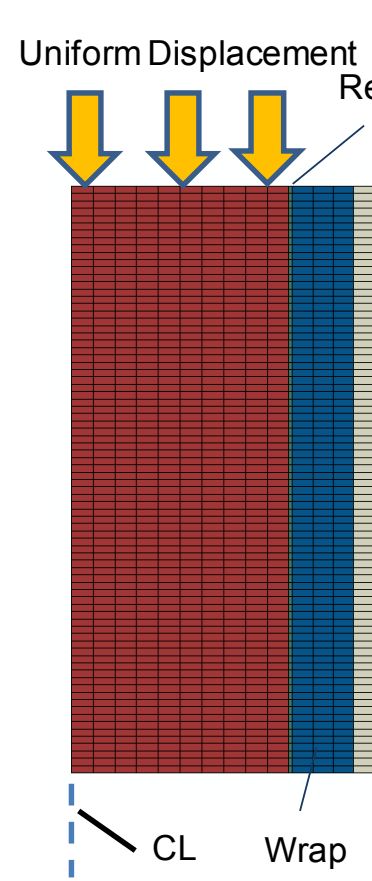

a) $2 \mathrm{D}$ axisymmetric model

Resin Layer

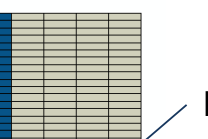

Potting Compound

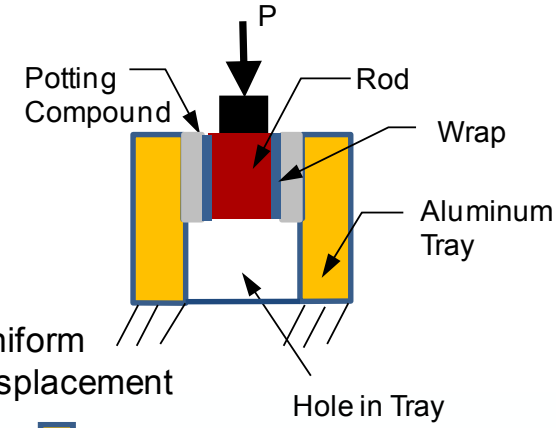

Displacement

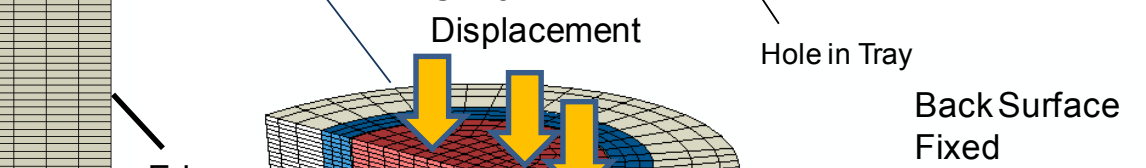

Edge

Fixed

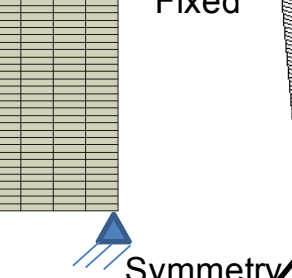

Surface Wrap

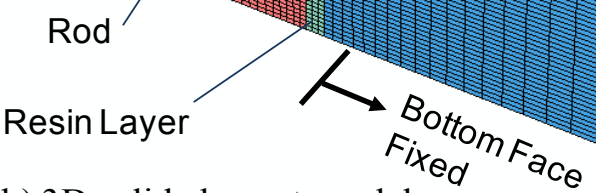

b) $3 \mathrm{D}$ solid element model

Fig. 8 2D axisymmetric and 3D solid finite element models. 


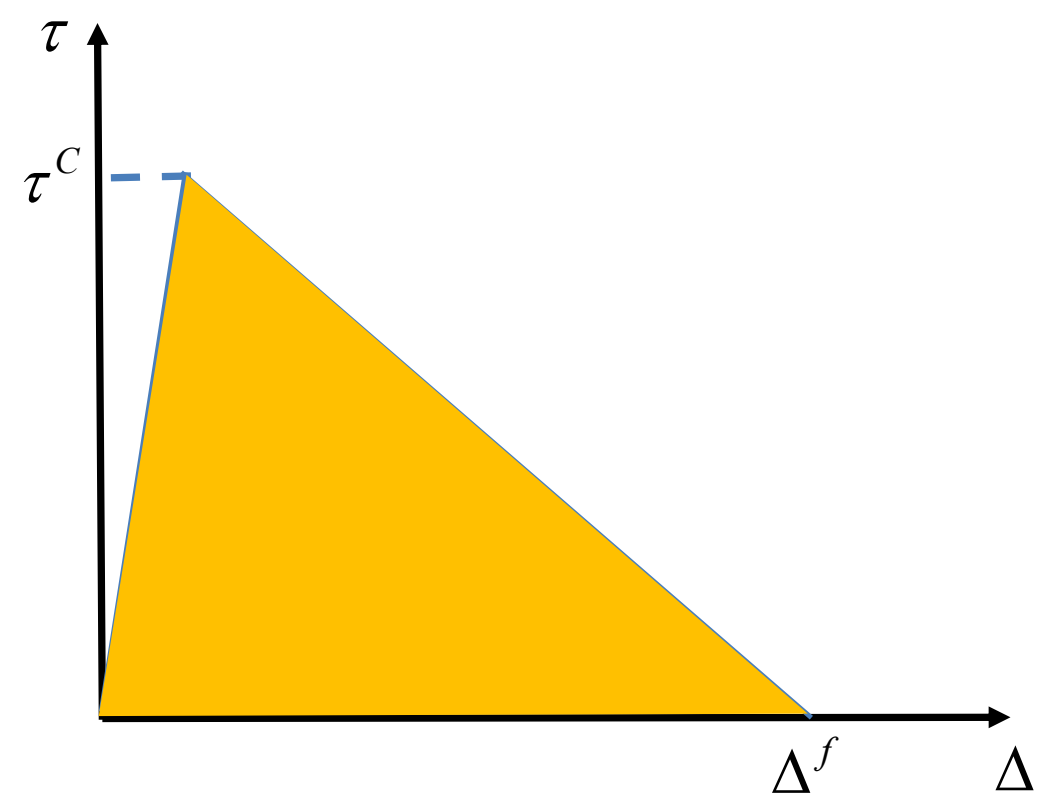

Fig. 9 Cohesive Law.
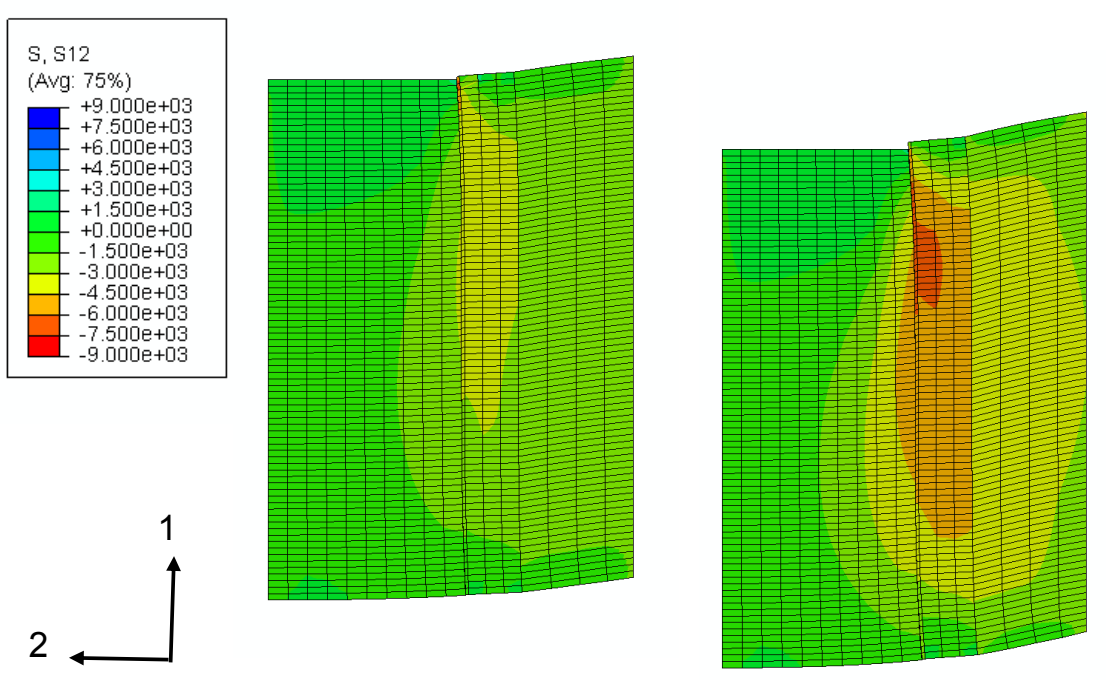

a) Stroke $=1.5 \times 10^{-3}$ in.

b) Stroke $=2.4 \times 10^{-3}$ in.

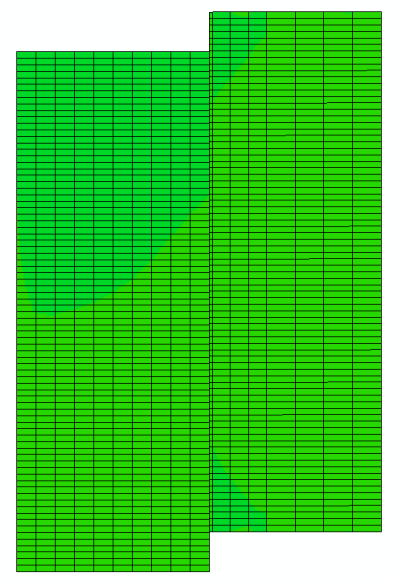

c) Stroke $=2.56 \times 10^{-3}$ in.

Fig. 10 Shear stress contour plots (2D axisymmetric model using cohesive surface for modeling rod-wrap interface). 




a) Stroke $=1.5 \times 10^{-3}$ in.

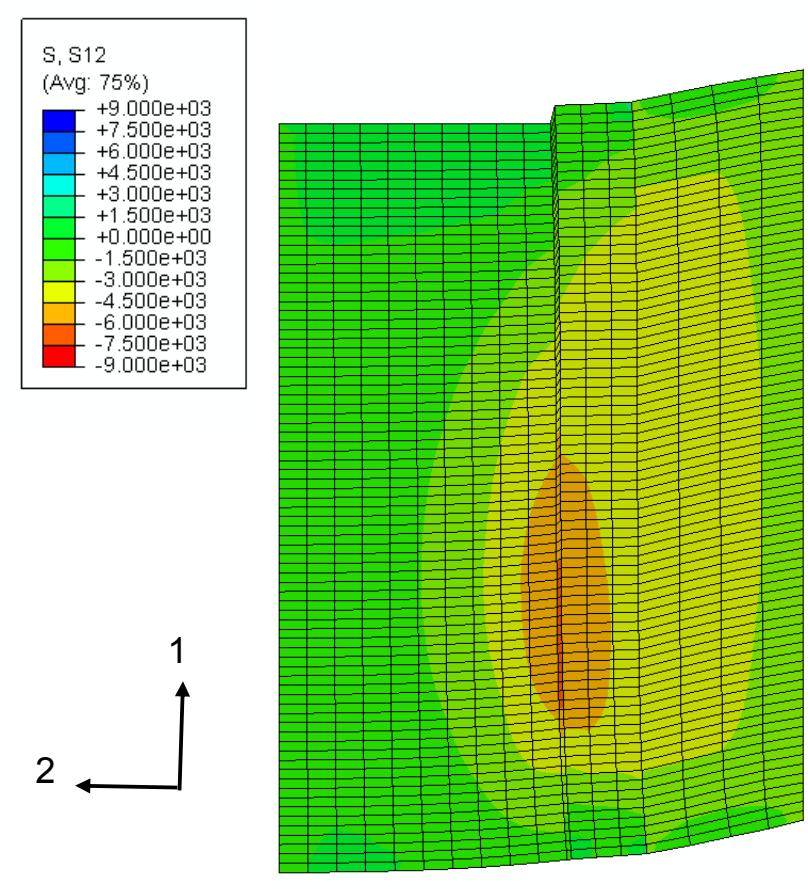

b) Stroke $=2.4 \times 10^{-3} \mathrm{in}$.

Fig. 11 Shear stress contour plots (2D axisymmetric model using cohesive elements for rod-wrap interface resin layer). 


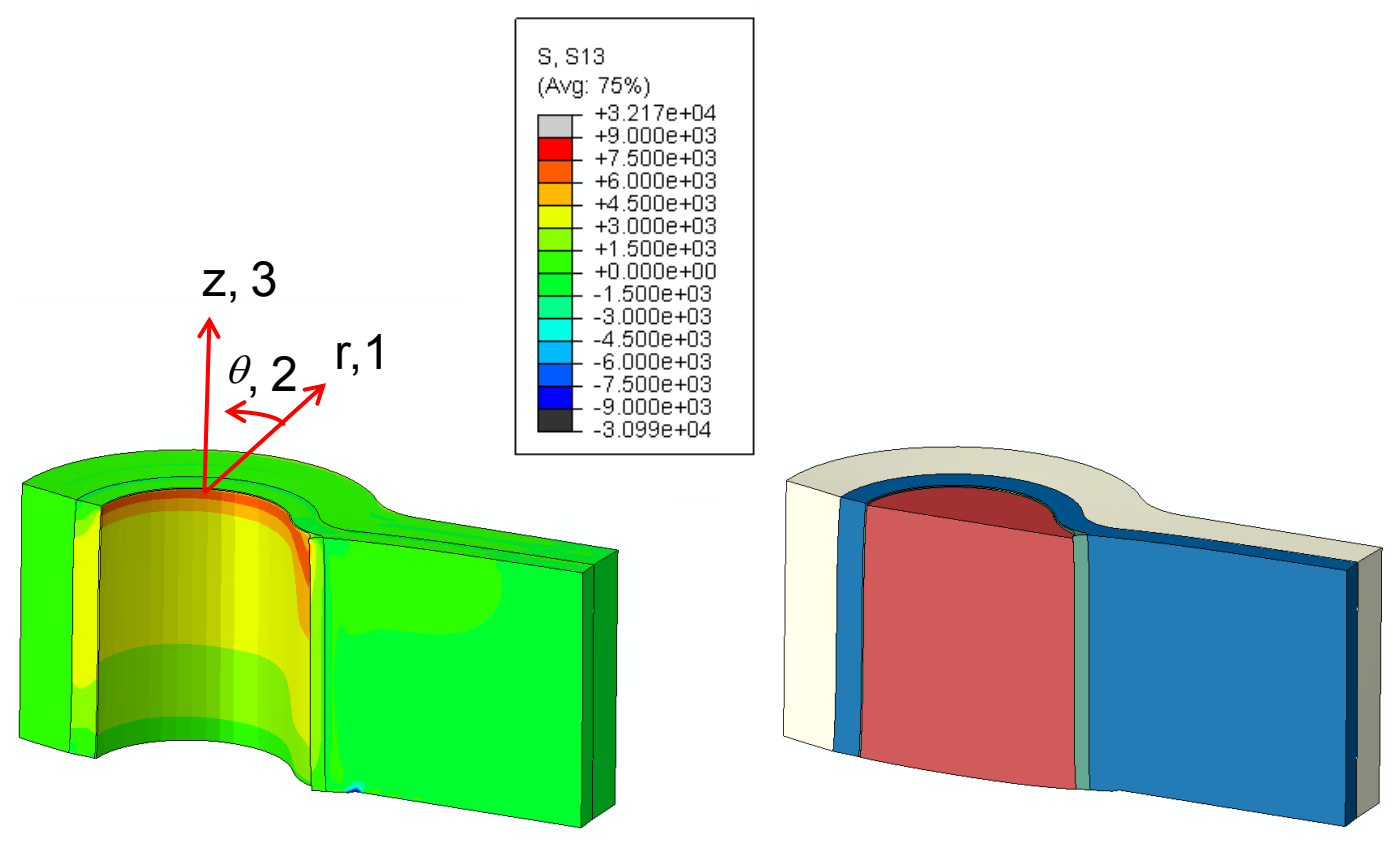

a) Stroke $=1.5 \times 10^{-3}$ in.
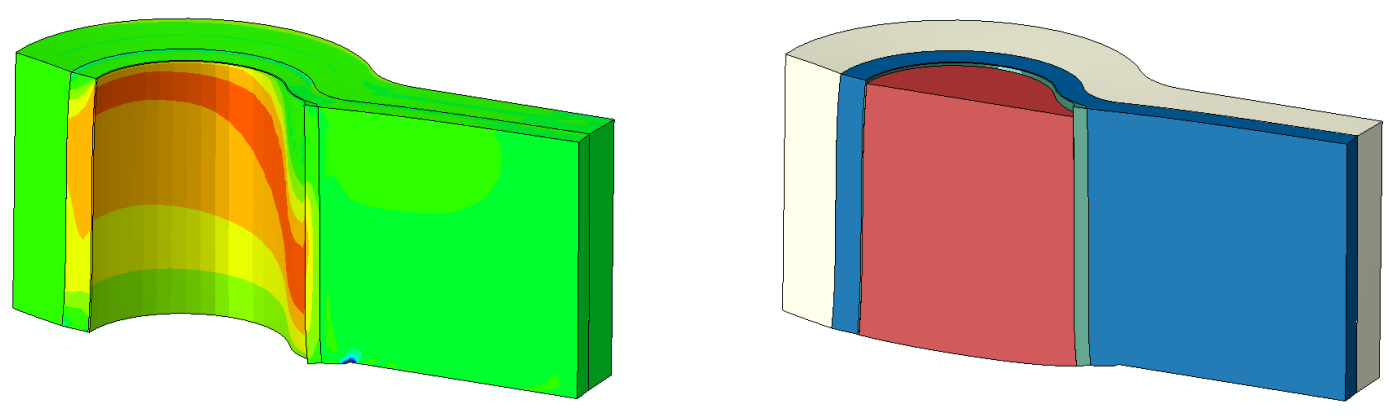

b) Stroke $=2.104 \times 10^{-3 i n}$.
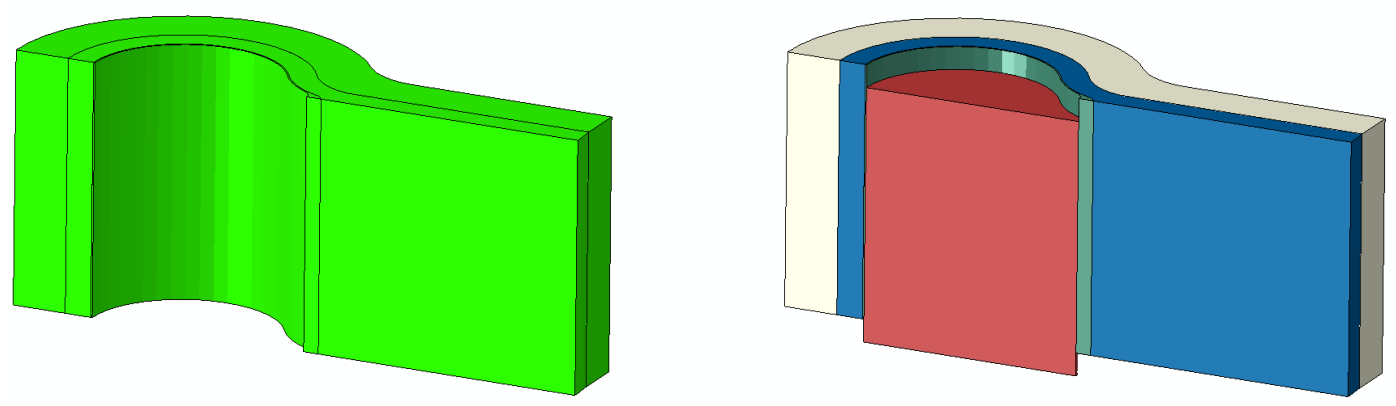

c) Stroke $=3.0 \times 10^{-3}$ in.

Fig. 12 Resin layer shear stress contour plots (Left) and deformation shape plots (Right). 


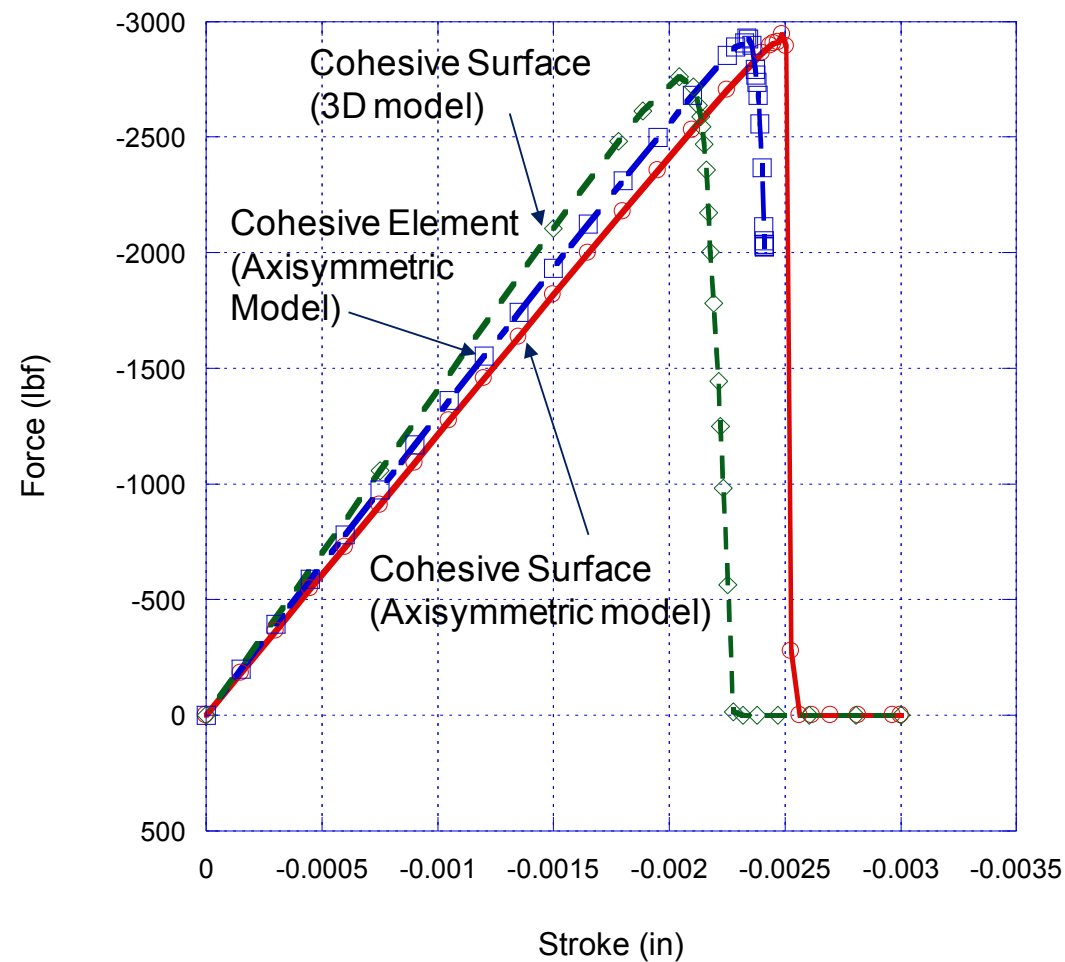

Fig. 13 Predicted push-out forces as a function of stroke by 2D axisymmetric and 3D solid element models.

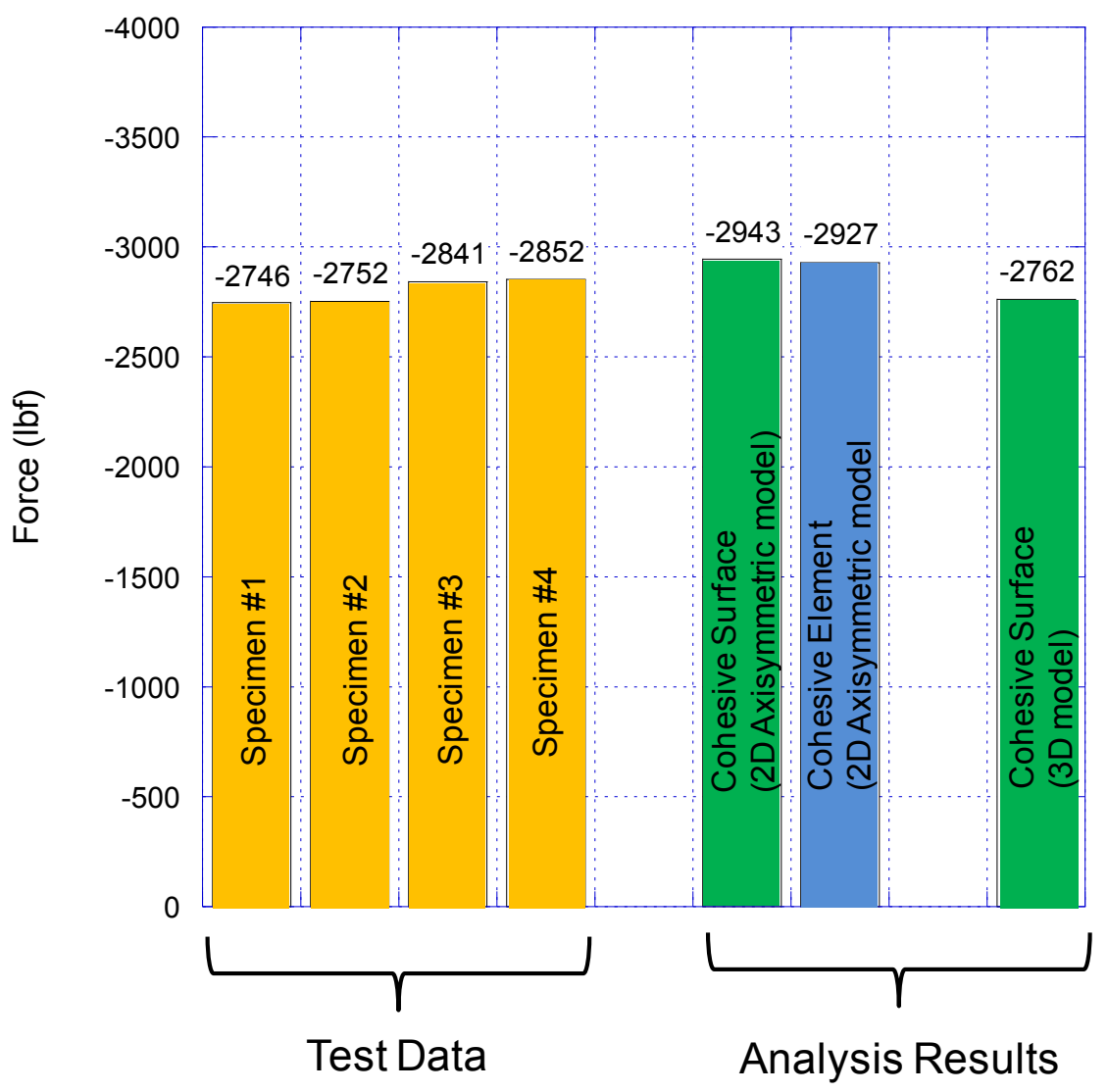

Fig. 14 Comparisions of test data and analysis results.

14

American Institute of Aeronautics and Astronautics 


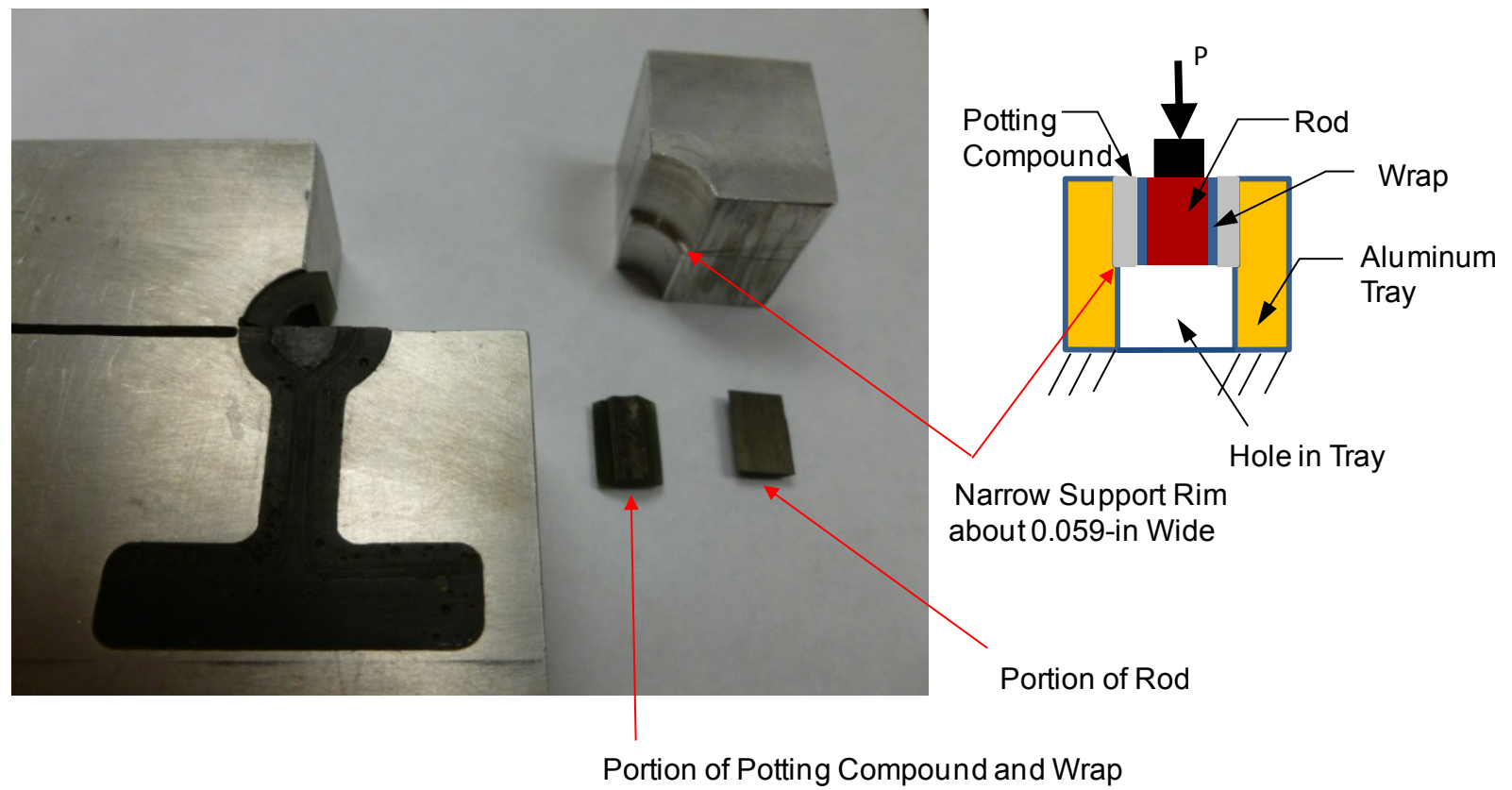

Fig. 15 Sectioned specimen revealing that potting compound and aluminum tray easily separated.

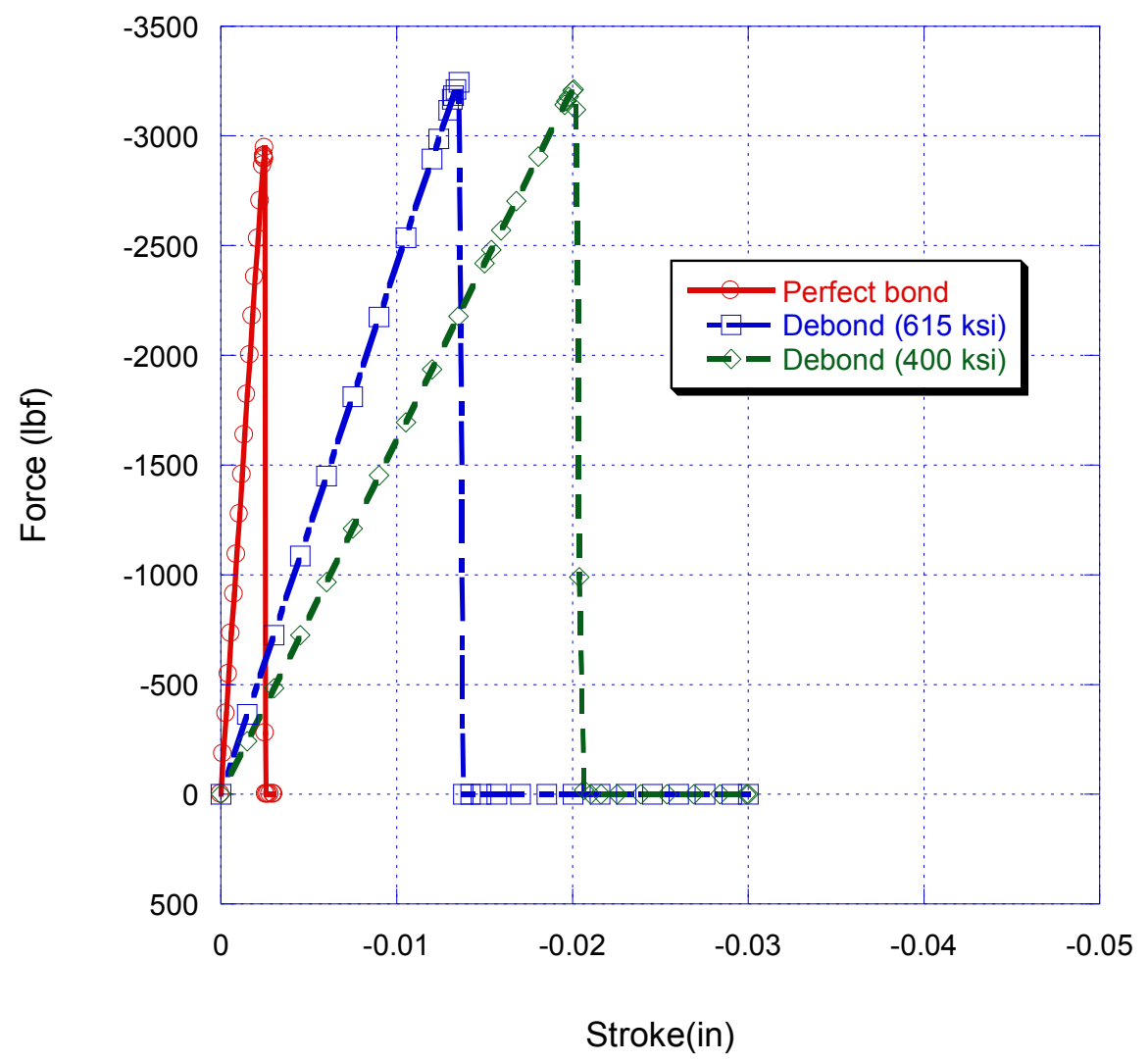

Fig. $16 \mathrm{ABAQUS}^{\circledR}$ force-stroke relationship predictions depending on the bondling conditions between the potting compound and aluminum tray and the Young's modulus of the potting compound. 


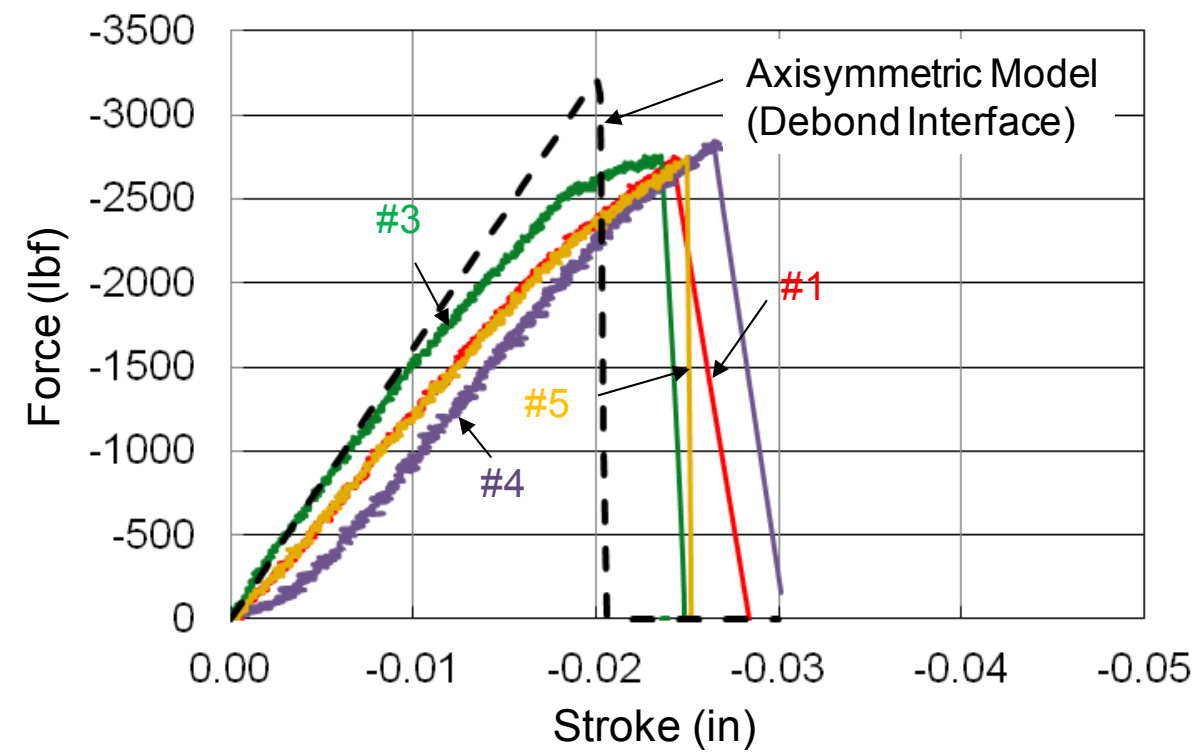

Fig. 17 Better correlation of test data and analysis results achieved with the assumption of debonding between the potting compound and the aluminum tray wall. 